\title{
HJ. SITI ROHANI ASYKARI: Berdakwah Lewat Majelis Taklim
}

\author{
Hj. Siti Rohani Asykari: \\ Preaching Through The Assembly of Taklim
}

\author{
Abd. Kadir M \\ Balai Penelitian dan Pengembangan Agama Makassar \\ Jl. A.P. Pettarani No. 72 Makassar \\ Email: amassoweang@yahoo.co.id
}

Naskah diterima tanggal 21 Desember 2012. Naskah direvisi tanggal 31 Desember 2012. Naskah disetujui tanggal 7 Pebruari 2013

\begin{abstract}
Abstrak
Penelitian ini membahas tentang biografi Siti Rohani Asykari sebagai ulama perempuan di Samarinda. Data-data penelitian ini merupakan hasil wawancara, dokumentasi dan studi pustaka. Wawancara mendalam terhadap Siti Rohani Asykari sebagai informan kunci dilakukan untuk mengetahui kehidupan pribadi, peran akademik dan sosialnya. Peran sosial yang dimainkan Hj. Siti Rohani Asykari samarinda yaitu; mendirikan Yayasan al-Jawahir, sebagai media pendidikan untuk anak-anak miskin di sekitar lingkungannya, aktif melakukan dakwah secara non-formal dengan membuat dan mendirikan majelis ta'lim buat para ibu. Siti Rohani Asykari juga aktif di Aisyiyah-Muhammadiyah. Di samping itu, ia juga bergelut dengan Golkar.
\end{abstract}

Kata kunci: ulama, perempuan, peran sosial

\begin{abstract}
The research discusses the biography of Siti Rohani Asykari as the Muslim women scholar in Samarinda. The data of the research were the results of interview, documentation and literature. The depth interview to Siti Rohani Asykari as the key informant was conducted to know the personal life, academic and social roles. The social activities carried out by Hj. Siti Rohani Asykari in Samarinda were to build al-Jawahir institution as a medium of education for poor children around the neighborhood, to be active in preaching non-formally by making the assembly of Taklim for mothers. Siti Rohani Asykari is also active in AisyiyahMuhammadiyah and Golkar, one of the famous political parties in Indonesia.
\end{abstract}

Keywords: muslim scholar, women, social roles

\section{PENDAHULUAN}

$\mathrm{U}$ lama dalam pengertian umum mendapatkan pengertian yang sepadan sebagai "guru" pengajar agama yang berasal dari kalangan Brahmana dalam agama Hindu, pendeta dalam agama Kristen atau Syekh dalam agama Islam. Pemaknaan ulama sebagai "guru" sebagai temapat belajar tentang agama berbeda dengan pengertian guru dalam pengertian umum. Di sini pemaknaan ulama melekat beberapa kualifikasi yakni kapasitas keilmuan, pengamalan dan akhlak. Anehnya, para peneliti lebih banyak meneliti ulama dari jenis kelamin pria dan jarang meneliti yang berjenis kelamin wanita.

Di kota Samarinda sebagai kota yang masyarakatnya majemuk dengan tradisi agama yang dinamis terdapat seorang agamawan wanita, yakni Hj. Siti Rohani Asykari. Dalam kehidupan sosial sehari-harinya, ia banyak menghabiskan waktunya untuk berdakwah, berceramah serta mendidik anak-anak demi menciptakan generasi cerdas dan membangun keluarga sakinah. Hj. Siti Rohani berpendapat bahwa untuk membangun 
sebuah bangsa dan negara yang maju, terlebih dahulu mestilah menciptakan generasi cerdas dan penguatan pembangunan keluarga sakinah. Dengan 2 (dua) pilar ini, akan diharapkan nantinya tercipta bangsa dan negara yang maju, dinamis dan antikorupsi.

Sebagai seorang perempuan, ia ingin menunjukkan bahwa kerja berdakwah bukan hanya kerja seorang laki-laki, akan tetapi kerja berdakwah adalah tugas semua insan manusia, di mana dan kapan pun. Hal ini dibuktikan oleh Hj. Siti Rohani dengan mentahbiskan dirinya menjadi seorang pendidik sekaligus juru dakwah, berceramah dari satu kampung ke kampung lainnya, yang dalam sehari-semalam melakukan aktivitas 4 (empat) tempat dengan kelompok pengajian yang berbeda pula.

Berawal dari pendidikan agama yang didapatkan dari KH. Jafar Sabhan, KH. Abdul Majid, Hj. Siti Rohani bertekad untuk mendirikan lembaga pendidikan dengan melihat situasi dan kondisi kampungnya serta kurangnya lembaga pendidikan yang murah, maka hati kecil Hj. Siti Rohani pun mulai meronta untuk mendirikan sekolah, yang di masa depan dikenal dengan Yayasan Al-Jawahir. Setelah melanglang buana di dunia akademik, ia pun terjun di dunia dakwah dengan mengajak ibu-ibu peserta didik di sekolahnya untuk mengisi waktu senggannya dengan belajar mengaji dan sharing pesan-pesan Ilahi.

Dariharikehari,pengajianitupun berkembang pesat, sehingga dengan semangat berapi-api Hj. Siti Rohani Asykari dari satu kampung ke kampung, satu desa ke desa lainnya mendirikan pengajian Majelis Ta’lim yang diisi dengan ceramah dari dirinya, tak jarang juga mengundang pendakwah lain untuk mengisi di pengajian tersebut.

Dari pengajian majelis taklim inilah, sehingga banyak tetangga desa atau tetangga kota yang mengundang Hj. Siti Rohani Asykari untuk berdakwah, dan tak jarang pula yang berkonsultasi berkaitan dengan problema kehidupan rumah tangga dan kehidupan sosial masyarakat.

Berdasarkan latar belakang yang telah dikemukakan, timbul pertanyaan penelitian yang diangkat sebagai masalah penelitian ini, yaitu: Bagaimana biografi dan karya tulis Hj. Siti Rohani Asykari sebagai elit agama di Samarinda Kalimantan Timur? yang dijabarkan dalam pertanyaan, bagaimana kehidupan pribadi, kehidupan akademik, dan kehidupan sosial Hj. Siti Rohani Asykari? serta apa karya-karya tulis Hj. Siti Rohani Asykari yang dapat dikemukakan?

Sepanjang penulusuran informasi mengenai kajian ulama perempuan terdapat dua referensi yang membahas masalah tersebut. Pertama, Ulama Perempuan Indonesia yang ditulis oleh Jajat Burhanuddin, di dalamnya mempublikasikan beberapa ulama perempuan diantaranya; Rahmah el-Yunusiah: Pelopor Pendidikan Perempuan, Nyai Ahmad Dahlan: Penggerak Perempuan Muhammadiyah, Sholihah Abdul Wahid Hasyim, Teladan Kaum Perempuan Kaum Nahdhiyyin, Prof. Dr. Zakiah Drajat: Pendidik dan Pemikir, Suryani Tahir: Perintis Pengajian Perempuan, Tuty Alawiyah: Pengembang Masyarakat Lewat Majelis Taklim, Aisyah Aminy: Aktivis Politik di Partai Islam, Hj. Hadiyah Salim: Pejuang Sosial Keagamaan, Rofiqah Darto Wahab: Qariahh dan Seniman Qasidah, Lutfiah Sungkar: Muballigh Keluarga Muslim, Ny. Hj. Chamnah: Tokoh Perempuan Tarekat Tijaniah, dan Hj. Nonoh Hasanah: Perintis Pesantren Putri di Jawa Barat (Burhanuddin: 2002: v-vi).

Buku 12 Tokoh Wanita Kaltim. Buku ini mempublikasikan 12 Tokoh Wanita Kaltim dianggap memberikan kemajuan pada perempuan Kaltim. Tokoh yang diangkat bergerak di berbagai bidang. 2 tokoh perempuan diantaranya bergerak di dunia pendidikan Islam yaitu Prof. Dr. Hj. Muriah dan Hj. Siti Rohani Asykari. Hanya saja beiografi ini diungkap secara (Suwinah Alwy dan Ba’asyir, 2007: v).

Secara terminologi (Glasse, 2002: 417), kata 'ulama bermakna orang-orang yang diakui sebagai cendekiawan atau sebagai pemegang otoritas pengetahuan agama Islam. Mereka adalah para imam masjid-masjid besar (agung), para hakim (agama Islam), dosen-dosen agama pada universitas (perguruan tinggi Islam), dan yang secara umum ia merupakan lembaga kelompok terpelajar atau kalangan cendekiawan keislaman yang memiliki hak penentu atas permasalahan keagamaan (Islam). Di Indonesia kata alim dipakai bagi seseorang yang jujur dan tidak banyak bicara; sedang kata ulama hanya digunakan untuk para ahli agama Islam saja, meskipun Presiden Soekarno menggunkakanya juga untuk para ahli agama lain sehingga dalam M.P.R.S. terdapat golongan ulama yang terdiri dari Ulama Islam, Ulama Khatolik, Ulama Kristen, serta Ulama Hindu dan ulama Budha (Ismuha dan Taufik, 1983: $3)$. 
Dalam penelitian ini yang dimaksud dengan ulama adalah ulama Islam, yaitu orang Islam yang ahli dalam agama Islam atau pemegang otoritas pengetahuan agama Islam dan diakui oleh masyarakat sebagai ulama berdasarkan kriteria konteks. Digandengkannya kata lokal pada ulama menunjukkan wilayah geografis pengaruh ulama. Istilah lokal dalam penelitian ini diperhadapkan dengan istilah nasional yang cakupannya lebih luas dari istilah lokal, meskipun batas nyata antara istilah lokal dan nasional terkadang sulit menbedakannya. Dalam hal ini, pengaruh ulama lokal secara dominan terbatas pada wilayah geografis tertentu, apakah tingkat kabupaten atau propinsi. Disamping itu, ulama (perempuan) dalam penelitian ini yaitu yang mendapat pengakuan masyarakat tentang keilmuannya. Pengakuan tersebut didasarkan pada akhlak yang lebih mulia dan aktivitas sosial merekadalan menjalankan amar ma'ruf nahi munkar di ruang publik. Institusi publik yang dimaksud yaitu yang bergelut dalam organisasi sosial-politik dan keagamaan seperti organisasi pendidikan keagamaan dan organisasi masjid.

Penelitian ini dilaksanakan di Samarinda propinsi Kalimantan Timur. Pada lokasi penelitian ini dipilih $\mathrm{Hj}$. Siti Rohani Asykari secara purposif dengan kriteria, sudah meninggal tetapi data primer tentang dirinya masih diketemukan, mempunyai karya tulis, dan mendapat pengakuan yang tinggi oleh masyarakat. Teknik pengumpulan data yang dipergunakan adalah Observasi terhadap lingkungan sekitar Hj. Siti Rohani Asykari, terutama kehidupan keagamaannya, Wawancara dengan berbagai informan yang relevan, memiliki informasi berharga tentang penelitian. Informan berasal dari tokoh masyarakat, tokoh agama, pengurus institusi agama, keluarga/kerabat ulama, murid-muridnya, dan anggota masyarakat lainnya, Studi pustaka dan dokumen yang berkaitan dengan penelitian, meliputi dokumen pemerintahan, catatan harian, karya tulis Hj. Siti Rohani Asykari sendiri, dan buku atau tulisan lainnya.

\section{PEMBAHASAN}

\section{Kehidupan Hj. St. Rohani Asykari}

Hj. Siti Rohani Asykari lahir pada tanggal 2 Agustus 1939 jelang Magrib. Buah hati dari pasangan M. Rasyidi (1. 1920) dan Hj. Fatima binti Muhdar (1. 1924). Awalnya ia diberi nama Nuriyah. Namun pada usia 2 tahun, ia meminta nama itu diganti menjadi Siti Rohani, karena menggemari sebuah lagu anak kecil.
Hj. Siti Rohani Asykari merupakan anak pertama dari 12 bersaudara yakni: Hj. Siti Rohani Asykari, Alm. Prof. H. M. Yunus Yazid (Mantan Rektor Universitas Mulawarman), Alm. Syahrun alRasyid (Mantan Camat), Alm. Drs. H. Syahruddin, Alm. H. Yusuf al-Rasyid, S.H, Hj. Rosdiah, Hj. Rostina Rasyid, S.H (Dinas Pendidikan Provinsi Kaltim), Hj. Haerani, Nailah, S.Pd, Maisarah, S.E, Fathul Manan, S.Sos. dan Kumdianah Sayuni.

Awalnya, Hj. Siti Rohani kecil diajar mengaji oleh ibunya dan mendapatkan didikan akhlak dari bapaknya. Dengan pengajaran mengaji dan pendidikan akhlak menjadi modal yang sangat berguna ketika menjadi guru. Selain itu, pendidikan non-formal Muhammadiyah telah mendarahdaging dalam kelurganya yang menerima langsung ajaran Muhammadiyah di Samarinda.

Dalam pendidikan formal, $\mathrm{Hj}$. Siti Rohani kecil memulai pendidikannya di Sekolah Rakyat Indonesia (setingkat Sekolah Dasar) dan lulus pada tahun 1952. Kemudian, ia melanjutkan pada Sekolah Normal Islam tahun dan lulus 1955. Untuk memperoleh ijazah Pendidikan Guru Agama, ia mengikuti Ujian Guru Agama. Selain pendidikan formal, ia memperoleh kajian kitab kuning dari berguru kepada KH. Abd. Majid, dan juga mendalami ajaran Islam kepada KH. Jałar Sabran di sekolah Normal Islam.

Pada tanggal 05 Maret 1958, tepatnya usia 19 tahun, ia menikah dengan H.M. Askari setelah setahun sebelumnya ia telah dilamar. Sebelum menikah, Hj. Siti Rohani sudah terjerumus dalam dunia pendidikan dengan menjadikan rumah neneknya sebagai sekolah penampungan dari hasil kelebihan Sekolah Rakyat di kampungnya. Dalam menekuni dunia pendidikan inilah, Siti Rohani dan M. Asykari saling kenal dan bahu-membahu dalam pendirian dan penguatan lembaga pendidikan hingga mereka melangsungkan pernikahan. Mulai tahun 1959, bersama suami tercinta, ia kemudian terus mengembangkan sekolahnya yang dinakhodai oleh H. M. Asykari sendiri sebagai kepala sekolahnya. Sejak berdirinya sekolah ini, Siti Rohani mengajar dengan status Pegawai Negeri Sipil Departemen Agama yang diperbantukan hingga 1993 dan dilanjutkan oleh menantu beliau Ahmad Marsuki.

Sekolah ini kemudian dikenal dengan nama Sekolah Dasar Islam (SDI) Al-Jawahir, yang berasal dari rintisan Sekolah Dasar. Dari tahun ke tahun, sekolah ini berkembang mulai dari TK, SD, MTS, 
MA dan bernaung di bawah Yayasan Al-Jawahir yang di dalam akta notaris tertulis tahun 1977. Yayasan al-Jawahir ini bergerak cukup maju dan terkenal di Samarinda hingga sekarang ini. Dalam mengelola Yayasan ini, ia dibantu oleh adik-adiknya dengan menggunakan dana pribadi dan bantuan swadaya masyarakat. Pembayaran/baru diterapkan pada tahun 1979, itu pun dengan semampunya. Niat belaiu untuk mendirikan yayasan adalah untuk membantu masyarakat dalam bidang pendidikan khususnya kalangan yang kurang mampu. Sehingga awalnya, sekolah dasar Islam dikenal sebagai "sekolah penampungan". Walaupun dengan image seperti itu, sekolah saat ini tetap diperhitungkan dan mendapatkan sambutan antusias, khususnya masyarakat Samarinda.

Walaupun darah Muhammadiyah kental dalam keluarganya, tetapi pendirian sekolah ini tidak mengatasnamakan organisasi Muhammadiyah. Sekolah ini bersifat netral terhadap organisasi apapun. Selain karena biaya yang terjangkau, sikap kenetralan ini pulalah sehingga banyak masyarakat yang menyekolahkan anak-anaknya di sekolah ini.

Berdasarkan wawancara dengan $\mathrm{Hj}$. Siti Rohani, awal pertama kali dalam pendirian sekolah, sebagian warga kampung mencibir karena menganggap wilayah tersebut sebagai daerah gersang. Namun berkat perjuangan dan ketekunan, sekolah ini berkembang hingga kini menjadi salah satu sekolah berprestasi di Kota Samarinda.

Dari buah cintanya dengan H.M. Askari lahirlah anak yang semuanya tumbuh menjadi dewasa dan bergelar sarjana. Mereka adalah Ir. Ahmad Taufik, MT; Wardiah, S. Ag; Sugnefal Wahdah; Aulia Mutaqien, S.Psi; Miftahurrizqa, SE dan Miftahul Agus, S.Pi. Dan sejak sang suami tercinta mengalami sakit sejak tahun 2010, maka Hj. Siti Rohani mulai mengurangi aktivitas bahkan berhenti total melakukan aktivitas dakwah, agar bisa fokus melayani kesembuhan suami. Akan tetapi, takdir Tuhan tak bisa dihentikan, sang suami tercinta pun meninggal dunia pada tanggal 15 Januari 2012.

Berbagai prestasi telah disematkan di pundak sang juru dakwah $\mathrm{Hj}$. Siti Rohani, mulai dari gelar Ibu Teladan tingkat kecamatan hingga tingkat Kalimantan Timur telah diraihnya. Penghargaan ini sangat pantas diberikan kepada ibu Siti Rohani, karena ia wanita ini berhasil mendidik keenam anaknya. Sebagai ibu, ia sering menjadi tempat bertanya bukan hanya bagi anak-anaknya, tetapi juga para ibu-ibu sekitarnya berkaitan dengan berbagai persoalan rumah tangga hingga persoalan nasional-keagamaan. Ibu Hj. Siti Rohani Asykari yang mengagumi KH. Ja'far Sabhan, KH. Sani Karim dan KH. Abdul Majid selalu memotivasi anak-anaknya agar melanjutkan perjuangan yang dirintisnya bersama suami tercinta. Ketiga tokoh agama inilah, Hj. Siti Rohani banyak belajar agama, baik dengan belajar langsung maupun juga sering melakukan konsultasi dengan mereka.

\section{Aktivitas dan Peran Sosial Hj. St. Rohani Asykari Lembaga Pendididikan}

Siapa yang tidak bahagia, ketika cita-cita yang ingin dicapai terwujudkan, begitu pula Hj. Siti Rohani Asykari cita-cita sejak kecil ingin mendirikan sebuah lembaga pendidikan hingga akhirnya lembaga pendidikan itu terwujud dan berkembang pesat. Sejak masa keemasan Islam, pendidikan Islam dapat dipetakan dalam dua arus utama aliran, yakni aliran konservatif dan aliran rasional. Aliran konservatif (al-Muhafizh) adalah aliran pendidikan Islam yang mempunyai kecenderungan "keagamaan" sangat kuat dengan ciri-cirinya hanya memaknai ilmu terbatas pada pengetahuan tentang Tuhan, berambisi pada keluhuran spiritual hingga bersikap "mengecilkan" dunia, dan menganggap ilmu hanya untuk ilmu. Titik ujungnya hanya dimaknai sebagai pewarisan budaya. Sedangkan aliran rasional adalah aliran yang berusaha mengaktualisasikan potensi-potensi (natiqah, ghadhabiyyah, dan shahwatiyyah) yang dimiliki individu sehingga esensi pendidikan adalah kiat transformasi ragam potensi menjadi kemampuan aktual, antara lain hikmah (kemampuan mengetahui, berpikir, menalar dan memilah), 'iffah (kemampuan mengendalikan keinginan sesuai dengan pertimbangan akal sehat), shajaah (kemampuan mengarahkan semangat/ keberanian selaras pertimbangan akal sehat) dan adalah (kemampuan menyeimbangkan antar berbagai potensi diri). Dengan pelbagai potensi ini dapat menjadikan manusia yang terdidik dengan pendidikan Islam mempunyai pola pikir dan cara pandang yang kritis-transformatif dan kritis-praksis terhadap globalisasi. (Mahmud Arif, 2009: 38).

Lembaga pendidikan yang tidak mempunyai afiliasi ke partai politik dan organisasi massa apapun, lembaga ini hanya bertujuan semata untuk meningkatkan pendidikan masyarakat miskin di sekitar tempat tinggalnya. Lembaga pendidikan yang didirikan bersama suaminya ini tidak 
membebankan biaya yang mahal untuk para peserta didiknya, biaya di tekan sekecil mungkin, agar para orang tua peserta didik tidak terbebani dengan pembiayaan sekolah anaknya.

Lembaga pendidikan yang didirikan oleh Hj. Siti Rohani Asykari kurang lebih sama dengan peranan pesantren sebagaimana dijelaskan oleh K.H. Said Aqil Siradj, yakni sebagai berikut:

1. At-Ta'lim, yakni proses transformasi ilmu pengetahuan. Proses interaksi keilmuan yang lebih mengedepankan kualitas dan menyeimbangkan antara fisik-metafisik, rasional-irasional, dan subtantif-formalistik.

2. Al-Tadris, pendidikan yang mampu menumbuhkan transformasi ilmu pengetahuan dengan berlandaskan pada totalitas pengalaman keilmuan. Proses pendidikan yang meliputi teori dan praktik.

3. Al-Ta'dib. Proses pendidikan yang mampu memberi ruang secara luas bagi proses kesadaran berbudaya, beradab dan menjunjung tinggi etika.

4. Al-Tarbiyah. Proses pendidikan yang menyerukan untuk berpegang teguh pada prinsip pengakuan bahwa Tuhan adalah penguasa alam semesta (Siraj, 2007: 49).

Peranan dan fungsi lembaga pendidikan Yayasan al-Jawahir mencakup al-ta'lim, at-tadris, al-ta'dib dan al-tarbiyah untuk peserta didiknya, supaya di kehidupan masa depan dapat tercerahkan dan menjadi insan yang berkualitas. Dengan modal visi dan misi ini, Yayasan al-Jawahir yang mengelola lembaga pendidikan mulai dari TK, SD, SMP hingga tingkat atas, banyak diminati dan berkembang pesat di kota Samarinda.

\section{Bergelut Dengan Partai Politik}

Partai politik merupakan organisasi yang didirikan dan membela kepentingan politik anggota, masyarakat, bangsa dan negara, serta memelihara keutuhan Negara Kesatuan Republik Indonesia (NKRI) berdasarkan Pancasila dan Undang-Undang Dasar Negara Republik Indonesia Tahun 1945 (Undang-undang Nomor 2 Tahun 2008 tentang Partai Politik). Hal ini pulalah yang membuat $\mathrm{Hj}$. Siti Rohani Asykari menapakkan kakinya dan bergabung dalam partai politik, khususnya dalam kelompok dakwah.

Sebagaimana diketahui bersama bahwa pada zaman Orde Baru, tiap individu yang menyandang status PNS secara otomatis bergabung dalam
Golongan Karya, tak terkecuali Hj. Siti Rohani Asykari. menyisihkan waktunya di sela-sela kesibukannya berkecimpung dalam kelompok dakwah Golkar. Oleh karena itu, pelibatan Hj. Siti Rohani dalam Golkar tidaklah boleh dipandang negatif, akan tetapi mesti di pandang sebagai konsekuensi menyandang status PNS.

Adapun beberapa kegiatan yang dilakukan bersama Golongan Karya di Kalimantan Timur, sebagai berikut:

5. Sejak tahun 1966, selalu aktif dalam perjuangan Orde Baru dalam wadah Kesatuan Aksi Wanita Indonesia. Kegiatan dilakukan di masyarakat melalui pengajian dan ceramah agama, emndukung pembangunan melalui program pemerintah dalam Pelita I hingga Pelita V.

6. Dalam kegiatan Pemilu 1977 sampai Pemilu 1987 selalu aktif dalam penggalangan ke desa (Karakterdes).

7. Setiap kegiatan Golkar, selalu mengambil bagian dan ikut Penataran Fungsional Pendidik 1986, untuk meyakinkan prpisis pendidik, mengajaka teman dalam pembinaan peningkatan loyalitas.

8. Pada tahun 1985 dilantik sebagai anggota Wanhat DPD II Golkar Kotamadya Samarinda. Menghadapi Pemilu 1987 diberikan kesempatan untuk calon anggota DPRD Tingkat II Kotamadya Samarinda tetapi menolak, karena mengutamakan tugas-tugas dibidang profesi.

9. Pada Musda HWK Propinsi Kalimantan Timur ke I, tahun 1984 melalui formatur terpilih dan dilantik menjadi Wakil Ketua II Himpunan Wanita Karya periode 1984-1988.

10. Musda ke IV Golongan Karya Tingkat I Kalimantan Timur terpilih menjadi Ketua Biro Wanita Periode 1988-1993.

11. Sejak itu aktif mengikuti rapat-rapat pleno, rapat Koordinasi dan lain-lain.

12. Tanggal 24 dan 25 Juni 1989 mengikuti Rapat Kerja Golongan Karya Tingkat I Kalimantan Timur.

13. Tanggal 1 dan 2 September 1989 mengikuti penjelasan Tingkat I tentang penyegaran Kader Golkar.

14. Menghadiri rapat kerja Nasional Departemen Wanita DPP Golkar pada tanggal Agustus di Jakarta, yang didahului oleh Seminar Wanita Indonesia di bidang Ekonomi.

15. Sejak tanggal 21 Nopember sampai dengan 15 Desember 1990 Biro Wanita mengadakan Serasehan Form Komunikasi Wanita Golkar 
dan berakhir di Tingkat Propinsi Kalimantan Timur.

Keterlibatannya di Golkar membuatnya ia banyak mendapatkan pengetahuan berkaitan problem masyarakat. Problem yang selama ini menjadikan masyarakat, khususnya kota Samarinda mengalami krisis moral dan spiritual. Oleh karena itu, Golkar bagi Hj. Siti Rohani Asykari merupakan wadah bertukar-saran dan info antara masyarakat elit dan masyarakat bawah. Akses informasi lebih banyak dikuasai oleh masyarakat elit yang terdapat dalam penguru Golkar, sedangkan masyarakat bawah nihil akan informasi, apatah lagi media pada zaman Orde Baru hanya sedikit yang bertahan.

Dengan keterlibatannya pula di Golkar, ia dapat melakukan dakwah di antara istri para pengurusnya, selain menjalin persahabatan akrab, Hj. Siti Rohani Asykari juga aktif memberikan nasehat dan petuah-petuah demi kelangsungan keluarga sakinah para pengurusnya. Dengan demikian, masuk dan bergabung di Golkar tidaklah menyurutkan perhatian $\mathrm{Hj}$. Siti Rohani terhadap dakwah agama, malahan makin hari makin bertambah seiring dengan keaktifannya di organisasi massa tersebut.

\section{Pengajian Majelis Taklim dan Pembentukan Keluarga Sakinah}

Hj. Siti Rohani Asykari di samping sebagai ibu rumah tangga yang sibuk mengurus anak beserta suaminya, ia juga sangat aktif di organisasi sosial yang bergerak di bidang keagamaan. Ia dikenal sebagai tokoh Aisyiah yang aktif memberikan pengajian di berbagai tempat, mulai dari kampung hingga kota. Bermula pada tahun 1955, ia membentuk perkumpulan Tadarrus Alquran Remaja Putri. Pada tahun 1980, Siti Rohani mendirikan dan mengajar di Majelis Ta'lim Al-Muafakat yang terletak di Gang Mastur Samarinda. Kemudian berturutturut Majelis Al-Wahab Sei Darma, majelis AlIsra yang terdapat Jl. Kakatua, Pengajian Yasinan Baiturrachim Sei Pinang Dalam, Majelis Ta'lim Zia'ul Haq yang terdiri dari Himpunan Maulid Habsy se-Kota Samarinda serta pengajian malam Rabu Gang Raji Samarinda.

Dengan keterlibatannya dalam memberikan pengajian di berbagai majelis taklim ini, Hj. Siti Rohani selain mengajar banyak pula menimba pelajaran dari para jamaah majlis taklim yang sering berkonsultasi. Kegiatan ceramah sering pula dilakukan di layar televisi - TVRI Kaltim dan RRI Samarinda, termasuk radio Swasta Darussalam.
Di radio berciri khas agama itu, dai mengisis rubrik khas agama itu, dia mengisi rubrik Keluarga Sakinah. Di sela-sela kesibukannya menjadi juru dakwah, ia juga menyempatkan terlibat aktif pada kegiatan-kegiatan di MUI Kaltim dan sering juga di undang membawakan ceramah organisasi tersebut. Adapun pertimbangan, ia masuk dan terlibat MUI yaitu karena motivasi ingin belajar serta belum adanya tokoh perempuan yang aktif saat itu.

Salah satu item yang difokuskan oleh $\mathrm{Hj}$. Siti Rohani Asykari adalah membentuk keluarga sakinah. Ia berpendapat bahwa keluarga sakinah adalah contoh dan figur serta teladan yang baik dalam masyarakat dan lingkungannya. Keluarga sakinah merupakan prototype keluarga yang ideal. Keluarga sakinah tidak hanya sebagai model dalam takaran-takaran spiritual dalam arti tekun dalam menjalankan ajaran agama, akan tetapi secara sosial dan ekonomi pun patut untuk dicontoh dan diteladani oleh orang lain. Kriteria-kriteria keluarga sakinah yang begitu rumit dan sulit menyebabkan kebanyakan orang tidak mampu mencapainya. Bagi sebuah keluarga yang mampu mencapai predikat keluarga sakinah sudah pasti memiliki kelebihankelebihan dalam aktifitas spiritual dan ekonomi serta sosial di tengah-tengah masyarakatnya.

Di samping menonjol spritualitas dan ekonominya, peran sosial keluarga sakinah dalam memberikan pencerahan kepada masyarakatnya juga sangat diharapkan. Partisipasi sosial dalam membangun masyarakatnya sangat diharapkan, masyarakat dimana ia menjadi bagian dari padanya. Kontribusi sosial keluarga sakinah dalam menata dan merubah wajah masyarakat lingkungannya sangat diharapkan, karena keluarga sakinah pada dasarnya merupakan satu keluarga yang sudah lulus uji dari berbagai sisi kehidupan. Sehingga dengan demikian apa yang nampak dari keseharian keluarga sakinah dapat diadopsi oleh anggota masyarakat lain untuk kemudian diamalkan dalam kehidupan sosial, baik secara pribadi maupun dalam kehidupan berkeluarga.

Selain memberi ceramah seputar keluarga sakinah, ia juga sharing ilmu keagamaan melalui majelis ta'lim dan kelompok-kelompok pengajian tersebut, setiap tahun $\mathrm{Hj}$. Siti Rohani juga menyelengarakan bimbingan (manasik) ibadah haji. Manasik haji bimbingan manasik haji khusus perempuan ia laksanakan sejak tahun 1980-2010. Ia termotivasi karena banyak pertanyaan yang diajukan kaum perempuan namun hanya pantas dijawab oleh perempuan. Motivasi inilah sehingga 
ia memenuhi panggilan Departemen Agama untuk memberikan bimbingan manasik haji untuk perempuan. Di samping itu juga pengalamannya yang naik haji pada tahun 1979 tanpa ada yng seorang pun yang memberikan bimbingan manasik haji. Peserta bimbingan manasik hajinya, mulai dari para ibu calon haji kalangan Dharma Wanita Kota Samarinda, masyarakat biasa di perkotaan, hingga ke kampung-kampung.

Dalam sebuah wawancara dengan jama’ah majelis taklim, salah satu jama’ah mengatakan bahwa:

kelebihan Hj. Siti Rohani dibanding para mubaligah lain yang ada di kota Samarinda adalah Hj. Siti Rohani dalam berdakwah tidak mementingkan kelompok, ia berada dalam posisi netral ketika memberikan sebuah solusi, sehingga para jamaiah kaya akan wawasan, ia persilahkan kepada para jama'ah untuk mengambil pendapat yang menurut para jamaiah tersebut terbaik. Makanya, Kami menganggap Hj. Siti Rohani Asykari layak dikedepankan sebagai tokoh ulama perempuan berdasarkan pengetahuan dan pengalaman hidupnya. Di samping itu, ia satu kata dengan perbuatan, tutur salah seorang jama'ah majelis taklim.

\section{Karya Hj. St. Rohani Asykari}

Semasa hidupnya, Siti Rohani Asykari memiliki beberapa karya tulis yang belum diterbitkan. Semuanya itu merupakan bahan ketika membawakan pengajian dan ceramah, serta manasik haji. Karya-karya tersebut yaitu:

16. Kepemimpinan Wanita menurut ajaran Islam. Bentuk buku tidak terbitkan. Tebal 9 halaman. Berisi tentang:

a. Sifat ideal pemimpin.

Dalam penjelasanya berkaitan dengan sifat ideal pemimpin, Siti Rohani menjelaskan terlebih dahulu sifat ideal pemimpin dari perspektif Barat, sebagai berikut:

1. Memiliki kemampuan mempengaruhi dan membujuk orang lain.

2. Memiliki kemampuan manejerial yang baik.

3. Mempunyai konsep korelasi di mana pemimpin yang efektif harus mampu menjadi sumber inspirasi bagi orang yang dipimpinnya.

4. Memiliki visi yang jelas serta mampu menterjemahkan visi tersebut sebagai misi yang dilaksanakan oleh bawahannya.

5. Memiliki sifat optimis dalam mengemban amanah organisasi.
6. Memiliki kemampuan mengadakan pendekatan dalam segala situasi.

Sedangkan dalam perspektif Islam, Siti Rohani mendeskripsikannya, sebagai berikut:

1. Mampu memimpin dan mengendalikan diri sendiri sebelum memimpin orang lain.

2. Memiliki kemampuan manajerial yang baik.

3. Memiliki konsep relasi yang baik dan mampu menjembatani berbagai perbedaan yang ada.

4. Visinya adalah Alqur'an, misinya adalah menegakkan kebenaran.

5. Memiliki sifat tawadhu dan mawas diri dalam mengemban amanah Allah. Memiliki sifat Siddiq, Amanah, Tabligh, dan Fathanah serta menyadari Allah mengaruniakan kemampuan yang berbeda-beda bagi setiap orang dan menerima dengan rasa syukur dan ikhlas.
a. Karakteristik pemimpin
b. Akhlak seorang pemimpin
c. Kedudukan wanita dalam Islam
Dalam menjelaskan kedudukan wanita dalam Islam, Siti Rohani menjelaskan bahwa antara pria dan wanita sama sekali tidak memiliki perbedaanperbedaan kedudukan, baik kedudukan sebagai hamba Allah, sebagai anggota keluarga, sebagai istri, sebagai ibu rumah tangga. Dalam tulisan ini, Sitti Rohani menyiratkan bahwa kaum wanita mendapatkan kedudukan yang sejajaran dengan para pria dalam Islam dengan pada ayat Alquran, misalnya QS. Al-Hujurat/49: 13

Artinya:

Hai manusia, Sesungguhnya Kami menciptakan kamu dari seorang laki-laki dan seorang perempuan dan menjadikan kamu berbangsa - bangsa dan bersuku-suku supaya kamu saling kenal-mengenal. Sesungguhnya orang yang paling mulia diantara kamu disisi Allah ialah orang yang paling taqwa diantara kamu. Sesungguhnya Allah Maha mengetahui lagi Maha Mengenal .

1. Tuntunan merawat jenazah, bentuk buku tidak diterbitkan. Tebal 16 halaman. Berisi tentang:
a. Dasar hukum merawat Jenazah
b. Tata cara perawatan jenazah
c. Hak dan Kewajiban terhadap Jenazah
d. Mensucikan jenazah
e. Pola kain kafan untuk jenazah
f. Mengkafani jenazah
g. Menshalatkan jenazah
h. Tata cara pelaksanaan shalat jenazah

2. Doa dan dzikir ibadah Haji dan Umrah. Bentuk buku, kulit karton warna kuning jilid dibukukan. 
Tebal 53 halaman. Berisi tentang:

a. Doa ketika hendak melakukan perjalanan (musafir)

b. Niat Umrah dan Haji

c. Doa memasuki kota Makkah

d. Doa ketika melihat Ka'bah

e. Doa tawaf

f. Doa Sa’i

g. Doa di Musdalifah dan Mina

h. Doa melempar Jumrah

i. Doa tawaf Wada'

j. Doa ziarah di Madinah

k. Doa menggunting rambut

1. Tayammum

m. Qashar dan Jama'

3. Makalah "Mendidik Anak bersama Rasulullah" ditampilkan dalam kursus Pembinana keluarga Sakinah oleh Yayasan Keluarga Sakinah tahun 2010. Tebal makalah 5 halaman.

4. Makalah 'Peran istri dalam Menciptakan Keharmonisan Keluarga'. Tebal makalah 6 halaman.

5. Makalah 'Manajemen Rumah Tangga', tebal makalah 6 halaman.

6. Ceramah 'Empat Tiga Anak dalam Alquran. 3 halaman, disampaikan pada tanggal 17 April 1983 di Masjid Raya Samarinda dan di Majlis Ta’lim Kalimantan Timur.

\section{PENUTUP}

Hj. Siti Rohani Asykari lahir pada tanggal 2 Agustus 1939 jelang Magrib. Buah hati dari pasangan M. Rasyidi (lahir 1920) dan Hj. Fatima binti Muhdar (lahir 1924). Awalnya ia diberi nama Nuriyah. Namun pada usia 2 tahun, ia meminta nama itu diganti menjadi Siti Rohani, karena menggemari sebuah lagu anak kecil.

Dalam kehidupan sosial Hj. Siti Rohani Asykari banyak aktivitas yang dilakukan, di antaranya: Membuat Yayasan al-Jawahir. Hj. Siti Rohani Asykari bersama sang suami tercinta mendirikan Yayasan al-Jawahir sebagai media pendidikan untuk anak-anak miskin di sekitar lingkungannya, aktif melakukan dakwah secara non-formal dengan membuat dan mendirikan majelis ta'lim buat para ibu. Sebagai mubaligh yang juga aktif di Aisyiyah-Muhammadiyah, ia tidak serta merta mengajak para ibu majelis ta'lim untuk bergabung ke Muhammadiyah. Di samping itu, ia juga bergelut dengan Golkar. Sebagai seorang juru dakwah dan pendidik yang berstatus PNS, maka mau tak mau harus bergabung dengan organisasi yang dibuat sebagai anti-komunis pada zaman Orde Baru.

Adapun karya-karya Hj. Siti Rohani Asykari. Hj. Siti Rohani Asykari selain berdakwah dengan lisan, ia juga berdakwah dengan pena. Ia mempunyai beberapa tulisan yang dibukukan untuk pengetahuan para jama'ah majelis ta'limnya. Di antaranya yang penulis dapatkan, yakni: Kepemimpinan Wanita Menurut Islam, Tuntunan Merawat Jenazah dan Tuntunan Haji dan Umrah.

\section{UCAPAN TERIMA KASIH}

Ucapan terima kasih kepada seluruh pihak yang turut membantu terlaksananya penelitian ini mulai dari awal sampai akhir. Ucapan terima kasih terkhusus buat Hj. Siti Rohani Asykari atas kesedian waktu untuk diwawancarai dalam rangka pengumpulan data.

\section{DAFTAR PUSTAKA}

Abdullah, Taufik (ed). 1983. Agama dan Perubahan Sosial. Cetakan Pertama. Jakarta. CV. Rajawali bekerjasama dengan Yayasan Ilmu Ilmu Sosial (YIIS).

Alwy AS, Suwinah dan Hadri Abasyir. 2007. 12 Tokoh Wanita Kaltim. Cet. I; Samarinda: Sprirt Grafindo.

As'ad, Muhammad dkk. 2011. Buah Pena Sang Ulama. Jakarta: Orbit.

Asykari, Siti Rohani. Tt. Kepemimpinan Wanita Menurut Ajaran Islam. tidak diterbitkan

Burhanuddin, Jajat. 2002.Ulama Pepempuan Indonesia. Jakarta: Gramedia Pustaka Utama.

Glasse, Cyril. 2002. Ensiklopedi Islam (Ringkas). Cetakan Ketiga. Jakarta: PT Raja Grafindo Persada.

Ismuha, dalam Abdullah Taufik (ed). 1983. Agama dan Perubahan Sosial.

Mahmud, Arif.2009.Pendidikan Islam Transformatif, Yogyakart: LKiS.

Santing, Waspada. 2007. Ulama Sulawesi Selatan; Biografi Pendidikan dan Dakwah. Makassar: Komisi Informasi dan Komunikasi MUI Sulsel.

Siradj, Said Aqil. 2007. Teks Pesantren Tentang Pendidikan Kebangsaan dalam Jurnal Edukasi: Jurnal Penelitian Pendidikan Agama dan Keagamaan, Vol. 5 Nomor 2, 